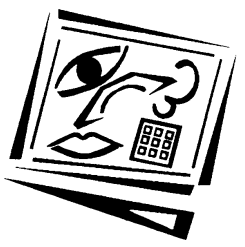

\title{
Engaging professional learning in online environments
}

\author{
Amani Bell
}

The University of Sydney

Gayle Morris

Deakin University

Much of what is regarded as effective professional learning is that which is situated, incorporates a social dimension and enables practitioners to converge in and around authentic practice. This article describes an inter-university online learning resource for tutors which is underpinned by a practice based approach to professional learning. The emphasis is on seeing authentic, discipline specific practice via a large bank of multimedia clips of experienced tutors and reflection on that action through the incorporation of reflective triggers. Evaluation suggests a fruitful way forward for supporting learning at work.

\section{Introduction}

Much of what is recognised to be effective professional learning is that which is highly situated, incorporates a social dimension and where communities of practitioners converge in and around authentic practice (Beckett \& Hagar, 2002; Fenwick, 2001; Lave \& Wenger, 1991). Many conventional professional learning programs fail in these regards, offering up decontextualised knowledge and skills, removed from context. Online learning offers the possibility of professional learning which is transformative, but as Alexander and Boud (2001) caution, such claims rarely bear out in practice: "much of the early use of the Internet in teaching has been to automate existing practices in a way that appears up-to-date but which is essentially a more timeconsuming and expensive way of reproducing existing practices" (p.5). In the disembodied environment of virtual space, designing professional learning programs that are effective from a learning perspective and transformative, and not merely extend conventional practices, can be a challenge.

The project at the heart of this article is an attempt to emulate qualities attributed to effective professional learning for university sessional academic staff in an online environment. Central to the design is exposure to authentic teaching practice across a range of disciplines, in reflective triggers and through the possibility of connecting with peers. While the focus of this article is on the online development, it sits within a broader framework of thinking about how professionals learn, and of the pedagogical models best to support them. Our approach starts with practice, that is actual teaching, and asks, following Schon (1995; p.29) "What kinds of knowing are already embedded in practice?" Within the context of professional learning, practice theory can be usefully interrogated for an understanding of how individuals become engaged within their environments and how best to facilitate learning. This perspective of how learning occurs within particular activity settings underpins the online design described in this paper. 
The enhancement of teaching quality and the corresponding growth of educational professional development are now well-established features across key international higher education contexts. Knight (2006) points to the establishment of national teaching and learning centres in Australia and England, and to the development of the scholarship of learning and teaching, as permanent manifestations of the increasing importance of teaching and learning within higher education (p.30). Within the Australian context Chalmers et al (2003, p. 11) identify the professional development of casual teaching staff as a priority, arguing for universities to adopt a "systematic and systemic approach" to the development of casual teaching staff. In more recent times, an Australian Learning and Teaching Council publication (2008), The RED Report, which built on earlier work in 2003, was an attempt, "to refocus attention on the issues surrounding sessional teachers in the university sector" (p.1). The intensity of sessionalisation appears to show no signs of abating, and thus mechanisms through which to enhance the quality of sessional staff continue to be at the fore.

At The University of Sydney, Faculty of Economics and Business and The University of Melbourne, Faculty of Economics and Commerce, the two faculties involved in this study, this is particularly a concern where undergraduate and postgraduate enrolments are high, and the demand for quality part time tutors is great. Both faculties employ a large number of casual tutors who teach small groups of up to 20 undergraduate students (classes can be larger at postgraduate level) and undertake associated marking and one to one consultation with students (Bell \& Mladenovic, 2008). In other contexts tutors are referred to as casual tutors, casual academics, teaching assistants, graduate teaching assistants, adjunct faculty, sessional staff and part time tutors. Our tutors come from a range of backgrounds: some are experienced teachers, while others are higher degree research students or have industry experience but little experience of teaching.

The National Tertiary Education Union (2007, p. 9) estimates that the number of casual staff (both academic and non-academic) in Australian universities has risen by $54 \%$ from 1995 to 2005. In one faculty there is the equivalent of 100 full time casual academics compared to 180 permanent academics (University of Sydney 2007). At the other faculty in 2005 there was the equivalent of 39 full time casual academics compared to 162 permanent academics (University of Melbourne 2005). Given the numbers and the role that tutors play in the overall learning experience of students, ensuring that tutors have access to high quality professional development is an imperative. As Johnston and Morris (2004) note:

In terms of effecting change in the quality of the learning experience for students the tutors play a pivotal role. Tutors are the first point of call for students and are likely to have the greatest interaction and thereby impact on student behavior and learning. They are the conduit between the lecturer and the student and are in many ways best placed to achieve a change in culture so necessary for imbedding real improvements in teaching. (p. 22).

Both faculties are at the fore of providing high quality professional learning experiences to casual staff; providing in house, discipline-specific professional development for new tutors, and ongoing professional development for more experienced tutors. The overall aim of the project described in this paper is to augment the existing programs of face to face professional development by providing online learning opportunities that deepen tutors' understanding of teaching, student learning, and their practice. The project builds upon an earlier resource created by the 
University of Melbourne's Faculty of Economics and Commerce in conjunction with the Centre for Studies in Higher Education. Critical to the redevelopment are the evaluation findings of a review of the University of Melbourne's online resource undertaken in late 2003 by a cohort of new and experienced tutors. The review included a survey that elicited qualitative responses of tutors' perceptions of functionality, including navigation and aesthetics, perceptions of usefulness, and projected patterns of use. A focus group followed with each cohort to flesh out and clarify observations made principally in the open ended section of the survey.

Tutors identified two key findings pivotal to their learning: that pedagogical knowledge is best developed in the context of each of the core disciplines, redolent of Shulman's (1994, p. 129) concept of "pedagogical content knowledge", and that having access to video clips of actual tutors drew attention to their own practice which was particularly powerful. The importance of observing others in shaping teaching practice is consistent with the finding of studies by Morris and Beckett (2005) and Bell and Mladenovic (2008), and of an inter-university video conference exchange (Morris \& Mladenovic 2005), where tutors consistently report observing others as particularly instructive. The redevelopment provided an opportunity to harness those aspects of the existing program which resonated with tutors and take them further. The redevelopment's core intent was to augment the disciplinary breadth of video clips available and to reconfigure the content in a way that enhanced reflective practice.

The process of creating the new website included deciding on topics for the new videos and creating the initial design of the site; scripting, filming and editing the new clips; writing supporting text for site; incorporating the existing University of Melbourne videos and audio interviews; adding supporting resources to the site; and final editing of all text. The site was then launched, and peer and tutor feedback sought. The next stage of the project involves making the suggested changes to the site and then gathering further feedback.

The article is structured as follows. We open with a discussion of key theoretical considerations that bring together practice theory (Beckett \& Hager, 2002; Gherardi, 2006; Nicolini, Gherardi \& Yanow, 2003) and evidence drawn from disciplinary styles in the scholarship of teaching and learning in higher education (Huber \& Morreale 2002). We then briefly describe the design of the online training program. In the sections thereafter, we present and discuss the results of the evaluation. Finally we reflect upon the efficacy on online professional development, in particular the extent to which a practice based approach is a fruitful way forward to advance our understanding and development of professional practice.

\section{Theoretical considerations}

Over several decades a substantial body of research related to professional learning or work based learning has developed. Of the research that contributes to our understanding of how professionals learn, work cuts across a diverse range of fields from organisational learning, adult learning, workplace learning, sociology and higher education. Within higher education the major theoretical developments influential in professional learning have arisen from what might loosely be termed as a 'conceptions based approach'. In this view the interest has been largely framed in the relationship between how teachers' conceptions influence students' approaches to study and the quality of the learning experience (Marton \& Saljo, 1976; Ramsden, 1992; Kember, 1997 Trigwell \& Prosser, 1996a, 1996b; Biggs, 1999). Findings of similar studies that employ 
the conception approach raise the possibility that there might be some sort of link between such conceptions and actual teaching practices; in other words changed thinking leads to changed doing. While a fruitful line of enquiry, there are limitations. A conception approach privileges a cognitive view of teaching enhancement and is therefore not able to exploit the complexity of teaching as an embodied practice enacted in various disciplinary cultures. While it is impossible to directly attribute certain models of professional learning to a conception based approach, the pervasive approach to professional learning tends to reflect cognitive models of change, where professional learning is seen as the imparting of skills and knowledge, delivered at arm's length from practice.

In recent times a number of authors (Kane, Sandretto \& Heath, 2002; Entwistle, 2003; Eley, 2006; Knight, 2006) have foregrounded practice in an attempt to redress some of the limitations of a conceptions based approach. While practice theory is welldeveloped in a range of disciplines, sociology, philosophy and management, particularly in organisational learning, it has limited currency within higher education teaching and learning.

Schon (1995) provides a useful starting point in thinking about practice:

...our knowing is ordinarily tacit, implicit in our patterns of action and in our feel for the stuff with which we are dealing. It seems right to say that our knowledge is in our action. And similarly, the workaday life of the professional practitioner reveals, in its recognition, judgment, and skills a pattern of tacit knowing-in-action" (p.29).

More recently Beckett and Hager (2002) mount a sustained philosophical argument to make the case that experience underpins most of the development of know how. For Beckett and Hager, 'know-how' is understood as a "type of knowing what to do in practice that is evident in the various intentional actions" (5). In this view practice is expressed as:

It is certainly not merely 'technique', although technical expertise (certain sorts of skilful dexterity, involving manipulation of materials, objects, processes and ideas) is essential. Technique is a necessary but insufficient component of practice. Practice involves a richer set of phenomena: a body of knowledge, a capacity to make judgments, sensitivity to intuition, and an awareness of the purposes of the actions are all involved in some way. (p. 12)

Taken together, they share a number of critical attributes: a sense of purposeful engagement, an emphasis on decision making, a recognition that knowledge or knowing sit under the surface and that may not necessarily be made explicit, and a recognition that it is difficult to separate out obtaining knowledge and applying knowledge. On this latter point, practice and knowledge are inextricably linked; we acquire knowledge through our daily work as we interact with social, physical and virtual environments.

Practice theory, as advanced by Gherardi (2006) and Nicolini, Gherardi and Yanow (2003), shares the centrality of an individual's engagement within their settings. Like Beckett and Hager, they argue that we cannot be understood as apart from our social and physical settings, but rather as embedded within them. As Nicolini et al argue, it is "in the 'here and now' of real time practices, knowing and doing are difficult to conceive of as separate ..." (2003, p. 26) and enables us to account for embodied learning, through attention to the actual doing of the work. 
A focus on practice also connotes a world in which activities and knowing always have a specific 'where' and 'when': they are always 'situated.' For tutors, practice is likely to be particular to a specific body of knowledge or discipline, and local, in that they will be working with specific cohorts in specific places, spaces, and times. In addition as with anyone who teaches, their experiences will be rife with inconsistencies, paradoxes and tensions. Nicolini et al (2003) argue that these are all fundamental and inescapable aspects of practice - the authentic practice, captured in the online video clips, exposes what Nicolini et al (2003) refer to as "breakdowns and disturbances" (p. 22). Redolent of Schon's work on reflection in action (1987), these provide powerful observational triggers for the tutor to engage in reflexive learning. Schon's work on reflection in action was a deliberate attempt to evoke learning from experience. Others such as Beckett and Hager (2002) have shown how such reflection enables us to transform experience into knowledge, which can then be represented and generalised to new contexts.

Practice based accounts of professional learning overlap with a number of theorists working with situative perspectives on workplace learning (for example, Fenwick, 2001; Lave \& Wenger,1991; Rogoff, 1990). They maintain that learning is grounded in the situation in which a person participates, not in the head of the person, as intellectual concepts are produced via reflection. Knowing and learning occur as a function of activity, context and culture. As was raised earlier, these views contrast with more traditional views of learning, where it is assumed that learning is an individual activity, and where knowledge is often presented as somehow 'out there' and out of context. This is consistent with a growing body of evidence based research that argues for professional learning that is embedded and attends to disciplinary nuances. The centrality of discipline based cultures and the significance for professional development is evident in the scholarship of teaching and learning. For example, Huber and Morreale suggest that:

Each discipline has its own intellectual history, agreements and disputes about subject matter and methods that influence what is taught, to whom, when, where, how and why. Each has a set of traditional pedagogies... and its own discourse of reflection and reform. (2002, p.2)

Put simply, professional development needs to address context specific issues, and speak in a language that is understood. Within the context of professional learning, and in designing online resources to support and stimulate such learning, practice theory can be usefully interrogated for an understanding of how individuals become engaged in their environments and how best to facilitate their learning. Practice understood in this way suggests that professional learning to support the development of tutors has to be more than just the development of a body of knowledge and techniques. The online professional learning design at the heart of this article was an attempt to respond to some of the limitations of traditional views of learning, and build from a serious consideration of practice.

Firstly, it was designed as a resource that reflects the context in which the tutor is actively participating as a starting point and includes a bank of visual representations in the form of multimedia clips. The clips are really the heart of the online resource and are categorised into a number of themes focusing on good teaching and learning. Secondly, tutors are encouraged to engage in a reflective dialogue with themselves, and others (when used in a development program), through a series of reflective triggers. Thirdly, while the resource attempts to ground itself in good practice, the 
theoretical framing of teaching and learning and the use of the reflective triggers, open up possibilities for alternative approaches.

\section{Overview of the site}

The website comprises video and audio interviews with experienced tutors and heads of department, and video clips of actual tutorials being conducted in many of the disciplines of the faculties. Where gaps emerged, scripted tutorials were filmed and used. Topics are based on key teaching issues and include questioning skills, strategies to promote student participation, teaching in a culturally diverse classroom, time management, small group management, effective opening and closing strategies and efficient feedback options. Each thematic area of the website is supported by text and scaffolding, and reflective triggers (Figure 1) that are designed to make explicit good practice as indicated in the video clips, and also to open up the possibility of alternative approaches. The supporting documents provide tutors with practical teaching tools.

The website is designed for sequential or non-sequential use, and can also be used in face to face development sessions. At one university, the site is integrated into the tutor development program with relevant videos played during the sessions and then discussed by the tutors.

\section{Q Whole Group Activities}

Focus Points: Role play part 2 - Tutorial with Rosina Mladenovic

Rosina asks students to prepare a role play for next week's class. This role play provides the students with an opportunity to show that they understand the concepts they've been learning about (debit and credit).

Rosina gives instructions (though perhaps more details could also be given, e.g. on a handout). She says that she'll ask a number of students to present next week - so they are prepared for that.

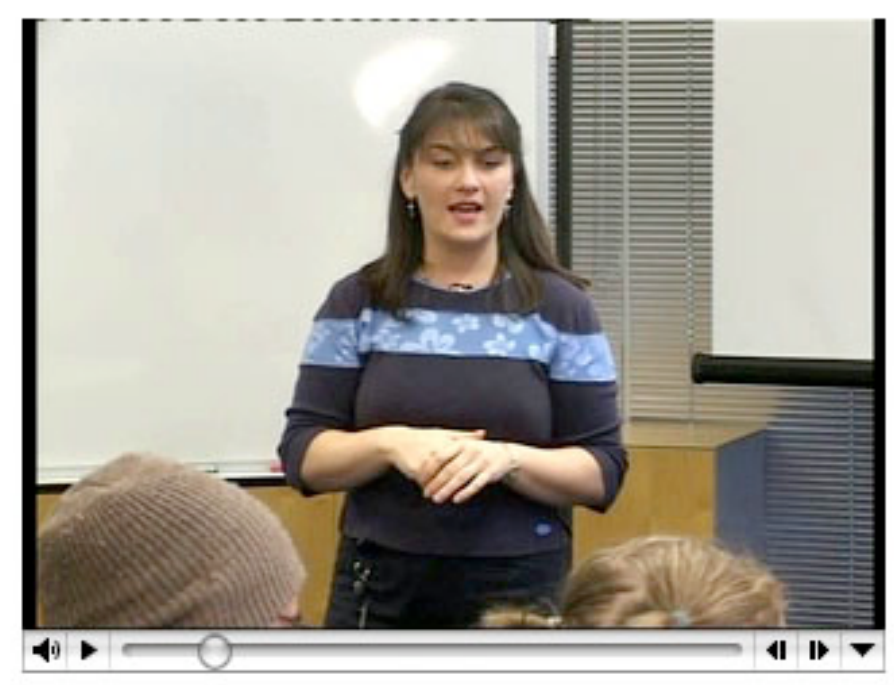

- QuickTime v6 or higher is required - Download QuickTime

At the following class,

Rosina reminds students of last week's role play and again praises the role players. This creates a nice link to the current tutorial, as well as acknowledging those students again and helping any nervous students feel better about presenting this week.

Think about how you might involve the rest of the class in actively observing the role plays, and what kind of feedback you could give to the students to further develop their understanding of the concepts under discussion.

Figure 1: Example of text accompanying a video clip 
The website was launched in March 2007 at the University of Melbourne:

http: / / tlu.ecom.unimelb.edu.au/tutortraining/

and in May 2007 at the University of Sydney:

http:/ / tutortraining.econ.usyd.edu.au/

As at March 2009 the University of Sydney site has received 130,970 total hits (1,555 unique), with the number of hits peaking at the beginning of each semester.

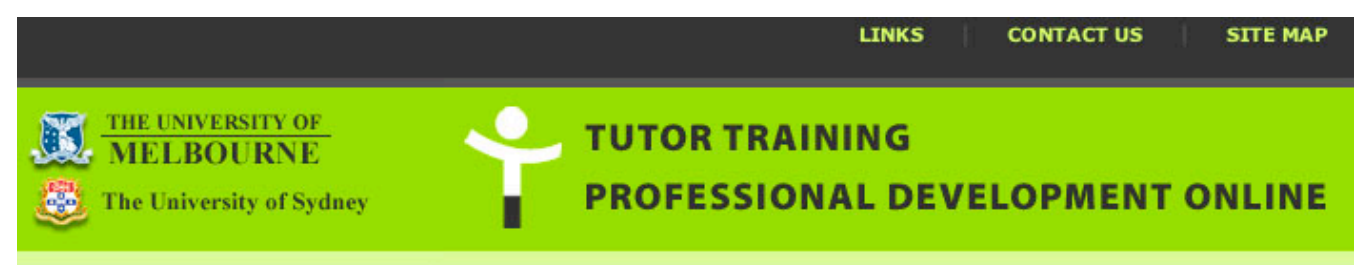

-Welcome

$\rightarrow$ Before You Begin

$\rightarrow$ The First Tutorial

Generating Engagement

$\rightarrow$ Classroom Strategies

Feedback \& Assessment

Diversity \& Inclusive Practice

Reflective Practice

\section{WELCOME}

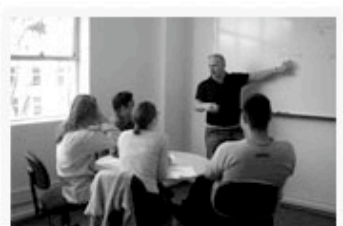
support tutors and sessional academ responsible for small group teaching in the disciplines within the Faculty of Faculty of Economics and Business. economics, finance, accounting, actuarial studies, management, and political

One of the key features of the website is that it incorporates video-clips of authentic and simulated classroom scenarios with 'real tutors' facilitating small group tutorials, in order to demonstrate a range of styles, approaches and strategies. It also features a number of The website has been designed to stimulate your thinking about teaching and learning for example each video-clip is accompanied by key teaching points, there are links to a range of self-assessment tools, additional resources; and a forum through which to engage in further conversation with other tutors, or a focused discussion facilitated by the occasional guest.

But while many of the approaches and strategies that you will observe are located within specific disciplinary contexts, for example management or accounting - there is much that is just good small group teaching. In that way, we hope that the website provides
models of small group teaching that can be modified to meet your specific needs.

Figure 2: Screen picture, project's website (http:/ / tutortraining.econ.usyd.edu.au/)

\section{Evaluation}

We found it useful to consider Treleaven's questions (2008; p. 3450) when planning the evaluation of the website: "Why are we evaluating? For whom are we evaluating? What are we evaluating? How will we evaluate these aspects?" We wanted to evaluate the website to determine if our objectives had been achieved, particularly whether it was useful to tutors in terms of deepening their understanding of teaching and student learning, and in assisting them to improve their practice. We also wished to use evaluative data to make improvements to the site such as usability and user interface; for the purposes of this article we are most concerned with the former. The evaluation consisted of tutor feedback gathered via a one hour session in which tutors used the website and then provided comments and ratings, and via quantitative and open ended questions in an end of program survey. While the evaluation is largely tutor focused, we added another dimension by having a peer reviewer provide feedback on the site, as recommended by Beattie (1994) and Lefoe, Philip, O'Reilly \& Parish (2009). 


\section{Tutor evaluation}

All tutors in the Faculty of Economics and Business at the University of Sydney were invited via email to take part in a one hour session mid-way through the semester, to provide feedback on the website. Twelve tutors participated and all gave their permission for their feedback to be used in this article. Tutors were paid at the 'other academic duties' rate for their participation. Three of the tutors were new to tutoring; the remainder had between one to six semesters of tutoring experience. The tutors were from a range of disciplines and there was an even split of male and female tutors.

Tutors spent an hour in a computer lab going through the website at their own pace and in whatever sequence they desired. The tutors provided ratings of and comments about each individual resource they viewed as well as ratings of and feedback about the site as a whole.

Table 1: Mid-semester tutor feedback on the website (percentage agreement, $\mathrm{n}=12$ )

\begin{tabular}{|l|c|c|c|c|c|}
\hline & $\begin{array}{c}\text { Strongly } \\
\text { disagree } \\
(\%)\end{array}$ & $\begin{array}{c}\text { Disagree } \\
(\%)\end{array}$ & $\begin{array}{c}\text { Neutral } \\
(\%)\end{array}$ & $\begin{array}{c}\text { Agree } \\
(\%)\end{array}$ & $\begin{array}{c}\text { Strongly } \\
\text { agree } \\
(\%)\end{array}$ \\
\hline The site is a valuable resource & & & & 25 & 75 \\
\hline The site is well organised & & & 8 & 25 & 67 \\
\hline I can move around the site easily & & 8 & 25 & 33 & 58 \\
\hline The site is visually appealing & & 8 & 47 & 50 \\
\hline I will use this site again & & & 8 & 33 & 58 \\
\hline $\begin{array}{l}\text { I would recommend this site to } \\
\text { other tutors }\end{array}$ & & & & & \\
\hline
\end{tabular}

Tutors were generally very positive about the website, with $100 \%$ agreeing or strongly agreeing that the site is a valuable resource, and that they would use the site again; $91 \%$ agreeing that they would recommend the site to other tutors.

In addition to this formal review, we used the end of semester survey to request feedback from all faculty tutors. Tutors were asked two of the same rating questions as in Table 1 above.

Table 2: End of semester tutor feedback on the website (percentage agreement, $\mathrm{n}=25$ )

\begin{tabular}{|l|c|c|c|c|c|}
\hline & $\begin{array}{c}\text { Strongly } \\
\text { disagree } \\
(\%)\end{array}$ & $\begin{array}{c}\text { Disagree } \\
(\%)\end{array}$ & $\begin{array}{c}\text { Neutral } \\
(\%)\end{array}$ & $\begin{array}{c}\text { Agree } \\
(\%)\end{array}$ & $\begin{array}{c}\text { Strongly } \\
\text { agree } \\
(\%)\end{array}$ \\
\hline The site is a valuable resource & & & 4 & 52 & 44 \\
\hline $\begin{array}{l}\text { I would recommend this site to } \\
\text { other tutors }\end{array}$ & & 4 & 48 & 48 \\
\hline
\end{tabular}

Similar to the mid-semester results, Table 2 shows that tutors agreed that the site was a valuable resource (96\%) and that they would recommend the site to other tutors (96\%).

Along with the quantitative data above, we also had access to qualitative data gathered during the mid-semester evaluation and the end of semester survey. We analysed the qualitative data in terms of the key project goals. Specifically we were interested in the extent to which authentic and simulated, discipline specific contexts and practices were useful in terms of professional development. Several of the tutors 
alluded to the power of the visual as a tool for professional learning. The following comments are illustrative of a broader view that supports that contention:

I really enjoyed this training aspect of the tutoring experience. The training was practical and gave you strategies you could implement in class immediately.

The 'common challenges' identified in this topic (classroom strategies) are an accurate reflection of problems that I have come across in my tutorials. Top marks for relevance and usefulness.

Although the site includes videos from a wide range of the faculties' disciplines, it does not include examples from every subject area within those disciplines. Tutors' views on whether teaching and learning were more meaningfully dealt with in a subject and discipline specific way differed. Some tutors felt that it was important to deal with specific teaching and learning strategies within a subject, or at the very least a discipline based framework: "I didn't find any videos from econometrics tutorials." and "[only] some [of the videos] were... applicable to me. I didn't even look at the Finance \& Economics \& Accounting examples."

Another essential consideration when developing the resource was to emphasise the centrality of performance or doing. The importance of being able to observe tutors engaged in actual practice were confirmed by the tutor feedback: "Relevant, real problems with some solutions. Videos are a good way to learn."; "It makes it so much easier to apply concepts/strategies to my own tutorials once I've seen someone else actually doing it."; "... observation of other experienced tutors can help new tutors to develop their skills."; "The in-class tutor videos are easy to listen to and related the point well though I really appreciate the descriptive text alongside each video"; "It's great to see exactly how other tutors do it in practice" and "we can learn some good practices from experienced tutors."

We designed the site to invite or evoke self and communal reflection. The tutor feedback provided evidence that the resource triggered reflective thinking about teaching practices: "Many of these ideas seem fairly obvious but the nuances can be brought out through thought and the section encourages you to think about how you do things."; "I figure I did well getting the groups going but there is always room for improvement. The resources will be helpful."; "[the topic of diversity and inclusive practice] is a 'blind spot' for me - I am aware that this is an important area but a bit unsure how to work towards it in my tutorials and unsure if I'm doing something wrong." and "the suggested technique [groupwork] seems like a very good strategy for overcoming the problem of passive students. Gareth [the tutor in the clip] provides good justification for this."

One tutor had already had a chance to try an idea from site and found it successful: "Great tip [to incorporate groupwork in tutorials] - I used it and it worked, particularly for non-English [speaking] background students."

Tutors made several suggestions on how the site could be enhanced. Tutors suggested that the site also include information about where to get help with things like resources and timesheets; additional journal articles related to the topics; more information on intercultural issues and students with non-English speaking backgrounds; conflict resolution information; example videos in the diversity and inclusive practice section; resources associated with the tutor development program and a link to the Blackboard learning management system. 
We also asked tutors who had not used the website to briefly explain why. Ten tutors responded. Five felt confident in their tutoring and did not feel a need to access the site; four did not have enough time to use the website, and one tutor forgot to use it.

\section{Peer evaluation}

We asked Sarah Howard from CoCo (the Centre for Research in Computer Supported Learning and Cognition) at the University of Sydney to carry out a review of the website. Howard has experience in both academic development and web design and so was ideally placed to provide an expert review. The evaluation covered three major areas: 1) alignment with overall project objectives - the broad topics covered by the website, and how the site supports project goals; 2) user interface - the physical elements of the website, e.g. links, icons, text formatting; and, 3) usability - whether the site is effective and easy to use. As noted, our interest is primarily in the alignment and as such will be the focus here.

In terms of alignment, the evaluation found that the website aligned with project goals and practices, as shown in Table 3.

Table 3: Website alignment with project goals and practices

\begin{tabular}{|l|l|l|}
\hline \multicolumn{1}{|c|}{ Practices } & \multicolumn{1}{|c|}{ Alignment } & \multicolumn{1}{c|}{ Examples } \\
\hline $\begin{array}{l}\text { Is thematic in } \\
\text { orientation }\end{array}$ & $\begin{array}{l}\text { The website consistently focuses } \\
\text { upon tutor training, facilitating } \\
\text { reflection, sharing, and discussion. }\end{array}$ & $\begin{array}{l}\text { Setting the scene (page) } \\
\text { Opening (page) } \\
\text { Self reflection checklist (page) }\end{array}$ \\
\hline $\begin{array}{l}\text { Is grounded in } \\
\text { authentic/ simulated, } \\
\text { discipline specific } \\
\text { context/ practices }\end{array}$ & $\begin{array}{l}\text { Concepts and themes presented in } \\
\text { the website are supported by } \\
\text { relevant discipline specific } \\
\text { examples, expert teacher discussion, } \\
\text { and supporting resources. }\end{array}$ & $\begin{array}{l}\text { Ice breakers (page) } \\
\text { Remembering names (PDF) }\end{array}$ \\
\hline $\begin{array}{l}\text { Emphasises the } \\
\text { centrality of } \\
\text { performance [doing] }\end{array}$ & $\begin{array}{l}\text { Concepts and themes are discussed } \\
\text { within the teaching practice, as a } \\
\text { tutor is teaching, continually } \\
\text { reaffirming the act of teaching and } \\
\text { doing. }\end{array}$ & $\begin{array}{l}\text { Helping students how to learn how } \\
\text { to learn clip 1 (video) } \\
\text { The role of the tutor while students } \\
\text { are working in groups (audio) }\end{array}$ \\
\hline $\begin{array}{l}\text { Has a strong visual/ } \\
\text { audio orientation }\end{array}$ & $\begin{array}{l}\text { Concepts, themes, and practice } \\
\text { examples are fully illustrated and } \\
\text { explained through high quality } \\
\text { audio and visual resources. }\end{array}$ & $\begin{array}{l}\text { Introducing the 1st tute (video) } \\
\text { Role play part 1 (video) } \\
\text { Using examples for other cultures } \\
\text { to illustrate key points (video) }\end{array}$ \\
\hline $\begin{array}{l}\text { Invites/ evokes self } \\
\text { and communal } \\
\text { reflection }\end{array}$ & $\begin{array}{l}\text { The website specifically addresses } \\
\text { student feedback and peer observ- } \\
\text { ation in the final section of the } \\
\text { website. All website sections invite } \\
\text { the tutor to evaluate and assess their } \\
\text { teaching practice, in response to the } \\
\text { video and audio examples. }\end{array}$ & $\begin{array}{l}\text { Clarifying expectations (page) } \\
\text { Feedback and Assessment (page) } \\
\text { Reflective Practice (page) }\end{array}$ \\
\hline
\end{tabular}

Howard concluded that "the website is focused and consistent, fully supporting all project goals and desired practices."

\section{Discussion and conclusion}

Taken as a whole the findings give support to the suggestion that a practice based approach in the design of online learning resources to enhance professional 
development is useful. However, the results should be interpreted in context of the small sample size. We will continue to seek feedback from a wider range of users and non-users of the website.

Specifically, the tutors and peer reviewer draw attention to the importance of the observation of other, more experienced tutors, in how teaching and learning is conceived. Almost all of the tutors foregrounded the importance of 'seeing' and 'doing' as useful in their professional development. The strengthening of a bank of easily accessible video clips to demonstrate a particular teaching strategy enables us to do this. Seeing others in the same or similar disciplines is an important part of the perception of usefulness. Even though the website covered a range of disciplines from within the two Faculties, some tutors wished to see videos from their specific disciplines. This is an important issue that we will consider in future augmentation of the site and that has implications for other academic development activities.

While seeing simulated and authentic practice was highly valued, many tutors found the descriptive script with reflective triggers a useful companion. The scripts enable us to focus the tutors' attention on aspects of practice that they are currently in, or are soon to be routinely immersed in. The reflective triggers encourage tutors to interrogate their own practice and each other's practice.

Adopting a practice based approach to the design of online learning resources for new tutors constitutes a promising way to understand knowing, and develop professional learning, that comes closer to our everyday experience. The 'take' on practice theory advanced in this article, is in keeping with Beckett's and Hager's conceptualisation of 'practice', and presents practice as robust and holistic, including the development of theory building, decision making and intention.

A practice based approach turns our attention to the local episodes of small group teaching from within the disciplines of economics, accounting, finance, management and political science. It is consistent with a growing evidence base of research that argues for professional development being embedded in and attending to disciplinary nuances. These representations of good practice provide the backdrop through which we can weave our own views on what constitutes good teaching practice, in order to stimulate the pedagogical imagination and practice of tutors. The incorporation of reflective triggers and discussion forums are devices intended to open up dialogue about teaching and learning.

However, the extent to which reflection contributes to the development of tutor's practice is more difficult to determine. So while tutors find the video recorded segments of other tutors practice particularly powerful, questions remains as to the extent that 'seeing' and reflecting or comparing with others 'doing' practice, leads to a change in practice. The evaluation undertaken does not allow us to make a claim against changed practice, only tutors' perception of its usefulness, although there was evidence of tutors incorporating strategies into their practice. Given the recent prominence in work based learning on attending to practice as the way to continually develop ourselves as professional practitioners (Morris \& Beckett, 2005; Beckett \& Hager, 2002; Beckett \& Morris, 2001), this is one area worthy of further consideration. The findings however are promising. 


\section{Acknowledgments}

This tutor training site was a collaborative redevelopment of an original site created by the University of Melbourne. The redevelopment was supported by a Teaching Improvement Fund grant from the University of Sydney. Staff from the Office of Learning and Teaching in the Faculty of Economics and Business at the University of Sydney and from the Teaching and Learning Unit in the Faculty of Economics and Commerce at the University of Melbourne worked on the site. We thank Dr Rosina Mladenovic for her substantial contribution to the project and the tutors and students who participated in the filming of the clips. We also thank colleagues in the Office of Learning and Teaching in Economics and Business for providing valuable feedback on this paper.

The redevelopment of the online professional development reflects an iterative process, spanning several years and involving two overlapping project teams. The views represented here are of the authors only and may not represent the original project teams' conceptualisation of professional development.

\section{References}

Alexander, S. \& Boud, D. (2001). Learners still learn from experience when online. In J. Stephenson (Ed.), Teaching and learning online: Pedagogies for new technologies. London: Kogan Page.

Beattie, K. (1994). How to avoid inadequate evaluation of software for learning. In K. Beattie, C. McNaught \& S. Wills (Eds), Interactive multimedia in university education: Designing for change in teaching and learning (pp. 245-258). Amsterdam: Elsevier.

Beckett, D. \& Hager, P. (2002). Life, work and learning: Practice in postmodernity. London: Routledge.

Beckett, D. \& Morris, G. (2001). Ontological performance: Bodies, identities and learning. Studies in the Education of Adults, 33(1), 35-48.

Bell, A. \& Mladenovic, R. (2008). The benefits of peer observation of teaching for tutor development. Higher Education, 55(6), 735-752.

Biggs, J. (1999). Teaching for quality learning at university. Buckingham: Open University Press.

Chalmers, D., Herbert, D., Hannam, R., Smeal, G. \& Whelan, K. (2003). Training, support and management of sessional staff. Final report, Australian Universities Teaching Committee. http: / / www.tedi.uq.edu.au/SessionalTeaching/

Eley, M. (2006). Teachers' conceptions of teaching, and the making of specific decisions in planning to teach. Higher Education, 51, 191-214.

Entwistle, N. (2003). Enhancing teaching-learning environments to encourage deep learning. In E. De Corte (Ed.), Excellence in higher education (pp. 83-96). London: Portland Press.

Fenwick, T. (Ed.) (2001). Sociocultural perspectives on learning through work. New Directions for Adult and Continuing Education Series. San Francisco: Jossey-Bass.

Gallison, P. (1997). Images \& logic: A material culture of microphysics. Chicago: University of Chicago Press. 
Gherardi, S. (2006). Organizational knowledge: The texture of workplace learning. Oxford: Blackwell Publishing.

Huber, M. \& Morreale, S. (Eds.) (2002). Disciplinary styles in the scholarship of teaching and learning: Exploring common ground. Washington, DC: The American Association for Higher Education and the Carnegie Foundation for the Advancement of Teaching.

Johnston, C. \& Morris, G. (2004). Off to a good START: Sessional tutors development programme. HERDSA News, December 2004, 22-25.

Kane, R., Sandretto, S. \& Heath, C. (2002). Telling half the story: A critical review of research on the teaching beliefs and practices of university academics. Review of Educational Research, $72(2), 177-228$.

Kember, D. (1997). A reconceptualisation of the research into academics conceptions of teaching. Learning and Instruction, 7(3), 255-275.

Knight, P. (2006). Quality enhancement and educational professional development. Quality in Higher Education, 12(1), 29-40.

Lave, J. \& Wenger, E. (1991). Situated learning: Legitimate peripheral participation. Cambridge; New York: Cambridge University Press.

Lefoe, G., Philip, R., O’Reilly, M. \& Parish, D. (2009). Sharing quality resources for teaching and learning: A peer review model for the ALTC Exchange in Australia. Australasian Journal of Educational Technology, 25(1), 45-59. http:/ / www.ascilite.org.au/ajet/ajet25/lefoe.html

Marton, F. \& Saljo, R. (1976). On qualitative difference in learning: 1 - Outcome and process. British Journal of Educational Psychology, 46(1), 4-11.

Morris, G. \& Beckett, D. (2005). Practices and contingent identities: A case study of casual university teachers. 4th International Conference on Researching Work and Learning, University of Technology, Sydney Australia, 12-14 December.

Morris, G. \& Mladenovic, R., (2005). Tutors talk: Inter-university perspectives on observation of teaching. HERDSA News, 25(3), 27-29.

National Tertiary Education Union (2007). State of the sector. South Melbourne: Policy Research Unit. [verified 1 Nov 2009] http:/ / www.nteu.org.au/publications/other/state_of_the_sector

Nicolini, D., Gherardi, S. \& Yanow, D. (2003). Knowing in organizations: A practice-based approach. New York: M.E. Sharpe.

Percy, A., Scoufis, M., Parry, S., Goody, A., Hicks, M., MacDonald, I., Martinez, K, SzorenyiReischl, N., Ryan, Y., Wills, S. \& L. Sheridan (2008). The contribution of sessional teachers to higher education (The RED Report). Australia Learning and Teaching Council. http: / / www.altc.edu.au/system/ files / resources / grants_sessionalteachers_report_june08.pdf

Ramsden, P. (1992). Learning to teach in higher education. Routledge: London.

Rogoff, B. (1990). Apprenticeship in thinking: Cognitive development in social context. Oxford University Press: New York.

Schön, D. (1987). Educating the reflective practitioner: Towards a new design for teaching and learning in the professions. San Francisco: Jossey-Bass. 
Schön, D. (1995). Knowing-in-action: The new scholarship requires a new epistemology. Change, Nov/Dec, 27-34.

Shulman, L. (1994). Those who understand: Knowledge growth in teaching. In B. Moon \& A. Mayes (Eds.), Teaching and learning in the secondary school, (pp. 125-133). London: Routledge.

Trigwell, K. \& Prosser, M., (1996a). Changing approaches to teaching: A relational perspective. Studies in Higher Education, 21(3), 275-284.

Trigwell, K. \& Prosser, M. (1996b). Congruence between intention and strategy in university science teachers' approaches to teaching. Higher Education, 32, 77-87.

Treleaven, L. (2008). A new taxonomy for evaluation studies of online collaborative learning. In L. Tomei (Ed.), Online and distance learning: Concepts, methodologies, tools, and applications (pp. 3449-3464). Hershey, USA: Information Science Reference.

University of Melbourne, University Planning Office (2005). Annual statistics book: Faculty staff by Faculty and Department. [viewed 3 Apr 2009]

http:// www.upo.unimelb.edu.au/Public/Mgmt_Info/StatsBook.html\#staff

University of Sydney, Office of Strategy Implementation \& Sustainability Planning (2007). Staff FTE: Faculties by occupation classification $\mathcal{E}$ appointment term. [viewed 9 Nov 2007, not found 7 Nov 2009] http: / / www.planning.usyd.edu.au/statistics/staff/staff07/staff_1c4.asp

Amani Bell is a Lecturer in the Institute for Teaching and Learning at the University of Sydney, and was previously at the University's Office of Learning and Teaching in Economics and Business. Gayle Morris is the Educational Designer in the Faculty of Science and Technology at Deakin University. Gayle was previously at The University of Melbourne, Faculty of Economics and Commerce, and was part of the project team prior to joining Deakin University.

Dr Gayle Morris, Educational Designer, Teaching and Learning Group Faculty of Science and Technology, Deakin University, Geelong 3217, Australia Email: gayle.morris@deakin.edu.au

Dr Amani Bell, Lecturer, Institute for Teaching and Learning

University of Sydney, NSW 2006, Australia

Email: a.bell@usyd.edu.au 